\title{
Homologous blood use and conservation techniques for cardiac surgery in the United Kingdom
}

\author{
Glenn N Russell, Steven Peterson, Susan J Harper, Mark A Fox
}

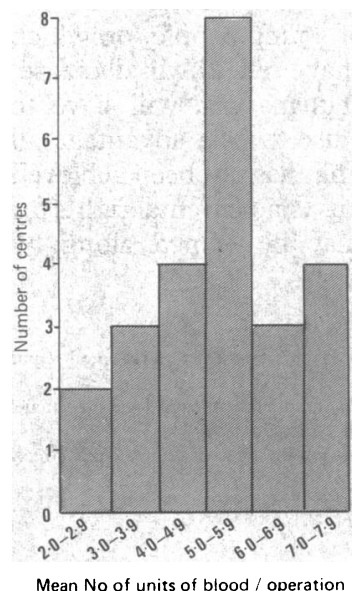

The distribution of blood use for adult open heart surgery in the United Kingdom

University Department of

Anaesthesia, Royal Liverpool Hospital, Liverpool L69 3BX

Glenn N Russell, FFARCs, lecturer

Susan J Harper, FFARCS, lecturer

\section{Regional Adult}

Cardiothoracic Centre, Broadgreen Hospital,

Liverpool

Steven Peterson, FRCS, registrar

Mark A Fox, FFARCS, consultant

Correspondence to: $\mathrm{Dr}$ Glenn N Russell,

42 Brookdale Avenue North, Greasby, Wirral, Merseyside L49 2NU.

\begin{abstract}
The transfusion laboratories of 32 cardiothoracic surgical centres for adults were surveyed to determine the donor blood requirement for open heart surgery in the United Kingdom. Details of the transfusion practice and the use of blood conservation techniques were sought from a representative senior cardiac anaesthetist at each centre. Suitable data were received from $\mathbf{2 4}$ transfusion laboratories $(75 \%)$ and 29 anaesthetists (90\%). The mean (SD) blood use was $5.07(1.53)$ units per operation. Seven centres routinely transfused fresh frozen plasma to all patients postoperatively. Experience with autologous deposit (three centres), "cell separators" (four centres), and the reinfusion of shed mediastinal blood (four centres) was limited. Prebypass phlebotomy for postbypass reinfusion (14 centres) and the infusion of residual oxygenator blood ( 27 centres) were the conservation techniques most commonly applied. In only nine centres was a postoperative normovolaemic anaemia to a haemoglobin concentration of less than $100 \mathrm{~g} / \mathrm{l}$ accepted.
\end{abstract}

Applying blood conservation techniques more widely would help to maintain blood supplies and reduce morbidity and mortality related to transfusion.

\section{Introduction}

The homologous blood requirement for cardiac surgery in the United States fell from eight units per patient in $1973^{1}$ to between one and three units in 1986. ${ }^{23}$ With a comprehensive blood conservation programme it is now possible to perform elective myocardial revascularisation without the use of blood in most patients. ${ }^{4}$ The aim of this study was to determine the homologous blood requirement for cardiac surgery in adults and to assess the application of conservation techniques in the United Kingdom.

\section{Methods}

Transfusion laboratories that supplied the 32 largest cardiothoracic centres which treat adults in the United Kingdom were asked to provide details of blood use for open heart surgery performed in the year from July 1986 to June 1987 . Centres in which a high proportion of paediatric operations were carried out or fewer than 200 operations a year were not included in the survey. If computerised data were available a hard copy of the records covering the study period was requested for analysis. If computerised data were not available then as much information as possible was manually extracted from written records. Data from a minimum of three months of the study period were required for inclusion in the analysis.

A reply paid questionnaire was sent to a senior consultant cardiac anaesthetist at each of the 32 centres requesting information on the practice of the centre as a whole. Information was sought on the use of specific conservation techniques, the routine use of blood products such as fresh frozen plasma, and the degree of anaemia considered to be acceptable after a cardiopulmonary bypass operation.

\section{Results}

USE OF BLOOD PRODUCTS

Suitable data were obtained from 24 of 32 (75\%) transfusion laboratories contacted. The remainder were unwilling or unable to provide sufficiently detailed information on blood products. Only four laboratories had computerised records at the time of the survey. The mean number of units of blood used for the entire period of hospitalisation was 5.07 (SD $1 \cdot 53$ ) units per operation, range $2 \cdot 4-7 \cdot 4$ units (figure). In seven centres fresh frozen plasma was infused routinely after all open heart operations, while in a further four it was given after all repeat operations.

In none of the centres were platelets infused routinely. Mean estimates of the requirements for fresh frozen plasma and platelets were not computed owing to lack of information.

\section{CONSERVATION TECHNIQUES}

Detailed information on conservation techniques was received from 29 anaesthetists representing $90 \%$ of the centres surveyed. The anaesthetists were not always from the centres that were able to supply data on blood use.

Preoperative-Facilities for preoperative autologous deposit: three centres had some experience of the technique, but only one had an established predonation programme, collecting one unit of blood per patient.

Intraoperative-(i) Prebypass phlebotomy for postbypass reinfusion: 13 centres used this technique occasionally, but only eight of these used it in more than half of their patients. (ii) Use of "cell separators" to process blood aspirated before and after bypass: four centres had some limited experience. None used these devices routinely. (iii) Reinfusion of residual blood in the oxygenator after bypass: 27 centres $(93 \%)$ routinely used this blood. Twenty three did not process blood in any way, three filtered the blood before infusion, and in one centre the oxygenator blood was concentrated by centrifugation before infusion.

Postoperative-(i) Reinfusion of shed mediastinal blood: four (14\%) of the survey centres routinely used this technique. In three of these it was used in over half of patients. In one centre the technique was limited to patients who had coronary artery surgery. (ii) Minimum acceptable haemoglobin concentrations during postoperative intensive care: 21 centres $(72 \%)$ transfuse to a haemoglobin concentration of at least $100 \mathrm{~g} / \mathrm{l}$; eight centres accept a concentration of $70-100 \mathrm{~g} / 1$ in the immediate postoperative period. Difficulty in obtaining blood for cardiac surgery was occasionally experienced by nine centres.

\section{Discussion}

The analysis of transfusion records undertaken in this survey should provide an accurate estimate of the requirements for donor blood for open heart surgery in the United Kingdom. Most of the responding centres provided data for at least six months of the survey period. The few transfusion records stored on computer was surprising, especially as there is software available. It is likely that more accurate data will become available only with the more widespread use of computers. No attempt has been made to compare blood use in individual centres or to compare our data with the published figures for the United States. It is essential to know the surgical techniques and duration and type of operation to determine overall blood use. 
These factors are not readily assessed in a survey such as ours. Blood conservation techniques, however, are generally applicable to cardiac surgical practice in adult patients irrespective of case mix and so have been included in the survey.

A large number of centres give fresh frozen plasma routinely in an attempt to reduce postoperative bleeding. Mild coagulation abnormalities occurring after cardiopulmonary bypass are fairly common and have many causes. If adequate heparinisation is carried out to prevent activation of the coagulation cascade by the bypass circuit this should prevent depletion of coagulation factors and fibrinolysis related to the perfusion. Although surface absorption of plasma proteins on to bypass apparatus occurs, soluble coagulation factors are not reduced sufficiently to cause abnormal bleeding postoperatively. ${ }^{6}$ Each unit of fresh frozen plasma exposes the patient to all the hazards of homologous transfusion and such treatment should be confined to managing proved coagulation defects.

The expansion in cardiac surgery and the awareness of infection transmitted by transfusion have heightened interest in techniques used to limit donor blood transfusion - for example, the use of preoperative autologous donation, which has been shown to be both safe and effective in patients presenting for cardiac surgery and could provide up to four units of blood in the month before operation.' In the United Kingdom autologous donation is little used, possibly owing to misconceptions regarding the risk of venesection in patients with coronary artery disease and to the logistic and financial problems of establishing a predonation programme.

Preoperative phlebotomy, intraoperative salvage, transfusion of residual oxygenator blood, and mediastinal reinfusion are practical elements of an effective blood conservation programme. Of these techniques, only the transfusion of residual oxygenator blood is practised by most centres in the survey. The most impressive blood conservation programmes have combined salvage techniques with the acceptance of normovolaemic anaemia in the postbypass period. ${ }^{489}$ The concept of postoperative normovolaemic anaemia has not been universally accepted. Weisel et $a l^{10}$ showed delayed myocardial metabolic recovery after crystalloid haemodilution to a minimum haemoglobin concentration of $70 \mathrm{~g} / \mathrm{l}$. Tector et al and Zubiate $e t a l$, however, reported good clinical results when patients with packed cell volumes as low as 0.22 were weaned from cardiopulmonary bypass. Indeed, provided myocardial revascularisation has been achieved Cosgrove et al have suggested that blood should be transfused only for specific clinical indications and not to maintain a predetermined packed cell volume. The practice of nearly three quarters of the survey centres is to aim at a haemoglobin concentration of at least $100 \mathrm{~g} / \mathrm{l}$ in the immediate postoperative period. Though allowing severe normovolaemic anaemia may be a controversial practice, lower haemoglobin concentration may be safely tolerated in selected haemodynamically stable patients with a consequent reduction in transfusion requirement.

There are probably two main reasons for the limited application of blood conservation in the United Kingdom. Firstly, the use of donor blood has no financial consequences for either the patient or the surgical centre. A formal programme of blood conservation is expensive, and the cost must be met from the surgical budget. This contrasts with the United States, where blood has a unit price and active conservation has been found to be cost effective."

Secondly, a bank of blood donated by volunteers is generally considered to be both safe and plentiful. Blood donated in the United Kingdom is now routinely tested for antibody to the human immunodeficiency virus (HIV). Between 1985 and 1987 only 92 of the 5840520 donations were HIV positive $(0.0016 \%)$." Although HIV transmission may occur from blood tested in the viraemic phase before seroconversion, the possibility is at present remote. Non-A non-B hepatitis is cause of post-transfusion hepatitis,${ }^{14}$ and screening is limited to detecting non-specific indicators such as raised hepatic transaminase activity in donated blood. The reported incidence after cardiac surgery in the United Kingdom ranges from $2 \cdot 4 \%$ to $3 \cdot 9 \%$. ${ }^{16}$ This compares with $14.6 \%$ in the United States ${ }^{1 \%}$ and $18.9 \%$ in Sweden. ${ }^{18}$ While the incidence of infection transmitted by transfusion in the United Kingdom is low, the potential problem is unlikely to diminish in the foreseeable future. Moreover, blood is a finite human resource and nine centres reported occasional difficulty in obtaining adequate blood supplies.

The current average requirement for donor blood for cardiac surgery is five units per operation. Though in giving blood products a careful balance of benefit and potential risk is at play, the routine administration of fresh frozen plasma should be discouraged. The more widespread application of conservation techniques should be considered to maintain blood supplies and further reduce the possibility of morbidity and mortality related to transfusion.

We thank all the respondents for their time and effort in providing the data for the survey.

1 Roche JK, Stengle JM. Open heart surgery and the demand for blood. $7 \mathrm{AMA}$ 1973;225:1516-22.

2 Yeh $\mathrm{T} \mathrm{Jr}$, Shelton L, Teh TJ. Blood loss and bank blood requirement in coronary bypass surgery. Ann Thorac Surg 1978;26:11-6.

3 Tector AJ, Gabriel RP, Mateicka WE, et al. Reduction of blood usage in open heart surgery. Chest 1976;70:454-7.

4 Cosgrove DM, Thurer RL, Lvthe BN, Gill CG, Peter M, Loop FD. Blood conservation during myocardial revascularisation. Ann Thorac Surg 1979; 28:184-8.

5 O'Shea MJ, Flute PT, Pannell GM. Laboratory control of heparin therapv. fClin Pathol 1971;24:542-6.

6 Bachman F, McKenna R, Cole ER, Najofi H. The hemostatic extracorporeal mechanism after open heart surgery. Studies on plasma coagulation factors and fibrinolysis in 512 patients after extracorporeal circulation. 9 Thorac and fibrinolysis in 512 patients

7 Love TR, Hendren WG, O'Keefe DD, Daggett WM. Transfusion of predonated autologous blood in elective cardiac surgery. Ann Thorac Sur 1987;43:508-12.

8 Thurer RL, Loop FD, Lytle BW, Cosgrove DM. The conservation of blood during cardiac surgery. Clin Cardiol 1979;2:155-7.

Utley JR, Moores WY, Stephens DB. Blood conservation techniques. Ann Thorac Surg 1981;31:482-90.

10 Weisel RD, Charlesworth DC, Mickleborough LL, et al. Limitations of blood conservation. I Thorac Cardiovasc Surg 1984;88:26-38.

11 Zubiate P, Kay JH, Mendez AM. Coronary artery surgery: a new technique with the use of little blood, if any. 7 Thorac Cardiovasc Surg 1974;68:263-7.

Brer RH, Engelman RM, Ranson JA Lemeshaw S. Blood conservation for myocardial revascularisation. Is it cost effective? I Thorac Cardiovasc Surg 1987;93:512-22.

13 Gunson HH Rawlinson VI AIDS update. Br Med $\mathcal{F}$ 1988:297:244.

14 Aach RD, Kahn RA. Post transfusion hepatitis: current perspectives. Ann Interm Med 1980;92:539-46.

15 Collins JD, Bassendine MF, Codd AA. Prospective study of post transfusion hepatitis after cardiac surgery in a British centre. Br.Med $\mathcal{f} 1983 ; 287: 1+22-4$ 16 Medical Research Council Working Party on Post Transfusion Hepatitis in a London Hospital. Results of a two year prospective study. I Hyg (Camb 1974;73:173-88

17 Knodell RG, Conrad ME, Ginsburg AL, Bell CJ. Efficacy of prophylactic gamma globulin in preventing non A non B post transfusion hepatitis. Lancet 1976;: $557-61$

18 Grillner L, Bergdahl S, Jyrala A. Non A non B hepatitis after open heart surgery in Sweden. Scand $\mathcal{F}$ Infect Dis 1982;14:171-5.

(Accepted 31 August 1988) 